\title{
Prevalence of late-stage presentation and associated factors of cervical cancer patients in Tikur Anbesa Specialized Hospital, Ethiopia: institutional based cross- sectional study
}

Mulugeta Wassie $^{1 *}$ and Beletech Fentie ${ }^{2}$

\begin{abstract}
Background: Cancer of the uterine cervix remains a main public health problem in Sub-Saharan Africa. About twothirds of patients with cervical cancer were diagnosed at late stage with contributing factors of out-of-pocket medical bill, looking for care out of conventional health settings and multiple visits to healthcare facilities before diagnostic confirmations in Addis Ababa. Therefore, the aim of this study was to identify prevalence of late-stage presentation and associated factors among cervical cancer patients in Tikur Anbesa Specialized Hospital (TASH).

Methods: Institutional based cross-sectional study was conducted from March to April 2019 in TASH oncology center. Data were extracted from patient's chart using structured checklist prepared in English and analyzed using STATA14.2. Binary logistic regression model was used to identify variables that affect the outcome variable.

Results: A total of 1057 cervical cancer patients were included in this five-years retrospective study. The prevalence of late-stage presentation among cervical cancer patients was $56.8 \%$. It was affected by being anemic $[A O R=1.55$, $95 \% \mathrm{Cl}(1.17-2.10)]$, came from Oromia region $(\mathrm{AOR}=0.65,95 \% \mathrm{Cl}(0.46-0.91)$ and Addis Ababa city $[\mathrm{AOR}: 0.5 ; 95 \% \mathrm{Cl}$ (0.34-0.73)], rural residency [AOR:1.88;95\% (1.38-2.56)] and age $\geq 60$ years [AOR:1.89;95\%Cl (1.12-3.20)].

Conclusion: The study revealed that the prevalence of late-stage presentation among cervical cancer patients is high. Being anemic, regions where patients came from, rural residency and age group $\geq 60$ years were statically significant. It is better to expand cervical cancer education for rural dwellers, expand cancer treatment centers and prioritize to patients with anemia and advanced age.
\end{abstract}

Keywords: Cervical cancer, Late-stage presentation, Ethiopia

\footnotetext{
* Correspondence: mulugeta2113@gmail.com

'School of Nursing, College of Medicine and Health Sciences, University of Gondar, Gondar, Ethiopia

Full list of author information is available at the end of the article
}

(c) The Author(s). 2021 Open Access This article is licensed under a Creative Commons Attribution 4.0 International License, which permits use, sharing, adaptation, distribution and reproduction in any medium or format, as long as you give appropriate credit to the original author(s) and the source, provide a link to the Creative Commons licence, and indicate if changes were made. The images or other third party material in this article are included in the article's Creative Commons licence, unless indicated otherwise in a credit line to the material. If material is not included in the article's Creative Commons licence and your intended use is not permitted by statutory regulation or exceeds the permitted use, you will need to obtain permission directly from the copyright holder. To view a copy of this licence, visit http://creativecommons.org/licenses/by/4.0/ The Creative Commons Public Domain Dedication waiver (http://creativecommons.org/publicdomain/zero/1.0/) applies to the data made available in this article, unless otherwise stated in a credit line to the data. 


\section{Background}

Cervical cancer remains a major public health problem in Sub-Saharan Africa. Predictions of the future years are also very frightening. Many challenges are associated with cervical cancer care in low- and middle-income countries including insufficient number of trained health care personnel, limited facilities and geopolitical factors such as wars, environmental disasters and HIV pandemic. Recent advances in molecular biology techniques make it possible to carry out a very early diagnosis of human papilloma virus (HPV) infections of genital organs among the women up to 30 years old $[1,2]$.

Two very effective prevention strategies for cervical cancer are vaccination against HPV and cervical cancer early screening with primary HPV testing followed by treatment of detected precancerous lesions. Realizing quick scale-up of immunization and two times lifetime uterine cervix screening in the world could prevent up to 13.4 million uterine cervix malignancy over the future half century $[2,3]$.

On the study conducted in Addia Ababa, the median health-seeking and diagnostic intervals of women with cervical malignancy were ten and ninety-seven days respectively with $75 \%$ of delayed diagnostic confirmation. Nearly $60 \%$ of patients with cervical cancer were diagnosed at late stage with the significant factors of out-ofpocket medical bill, looking for care out of conventional health care areas and several visits to health settings before diagnostic confirmations [4-6].

The etiology of cervical cancer was thought due to breaching social taboos or undertaking unacceptable behaviors and the supposed benefits of modern treatment were very low. Traditional remedies were the most preferred treatment options for early stage of the disease though most cases presented at advanced stage in which treatment options are ineffective. Limited awareness and inaccessibility of appropriate health services were independent predicting factors of late-stage presentation [7].

Nearly $64 \%$ cervical cancer patients were diagnosed with late-stage of the disease (IIIB-IVB) [8]. About $45 \%$ of cervical cancer patients presented with late stage (FIGO Stage III) and most (91.4\%) histology type was squamous cell carcinoma. The five-year survival across stages was $50 \%$ with predictor of FIGO staging (62\% stage II vs $45 \%$ stage III) [9-13]. Therefore, the aim of this study was to identify prevalence of late-stage presentation and associated factors among cervical cancer patients in Ethiopia.

\section{Methods}

\section{Study design, period and area}

Institutional based cross-sectional study was conducted in the oncology center of TASH, Ethiopia, from March to April 2019. TASH is the biggest referral public hospital in Ethiopia established in 1972. It is the training center of health professionals with undergraduate and postgraduate programs and others paramedics. The hospital is staffed by many health professionals from various disciplines. It has over 800 beds and the beds reserved for cancer care are 20. It is the only oncology center in Ethiopia and the only cancer registry center for Addis Ababa.

\section{Populations}

All medical records of the women diagnosed with cervical cancer in TASH cancer center from January 1, 2014 to December 31,2018 were study populations. Cervical cancer patients with medical charts that were incomplete and not found during data collection were excluded in the study.

\section{Sample size and study variables}

All women with cervical malignancy diagnosed at TASH beginning January 2014 to December 2018 was the sample size. Profiles of all women with cervical malignancy diagnosed and treated from January 2014 to December 2018 were evaluated and 1057 medical records that met the inclusion criteria were selected. Stage at presentation of cervical cancer was the outcome variable whereas sociodemographic, pathological and clinical characteristics were explanatory variables.

\section{Operational definitions}

Stage at diagnosis: the revised FIGO staging for carcinoma of the vulva, cervix, and endometrium was used [14].

Late stage: late stage at presentation was to mean patients presented with FIGO stages III and IV.

Anemia: patients' hemoglobin level below $12.0 \mathrm{~g} / \mathrm{dl}$ was classified as anemic [15].

Comorbidity: The presence of any conditions (mentioned in the Carlson comorbidity Index [16] other than cervical cancer at diagnosis.

Substance use: Patients who used one, two or all of the three substances (cigarate, chat and alcohol) [17].

\section{Data collection tools and quality assurance}

Data was collected from the patients' medical records using structured check list. The checklist consisted three parts: sociodemographic, pathological and clinical characteristics. Two master's holders in clinical oncology nursing supervised the data collection process and three nurses with bachelors of science in nursing were data extractors. Pretest of the checklists was done to test the checklists' reliability with real data collection and essential modifications were made accordingly. 


\section{Data processing and analysis}

The extracted data were entered and checked using Epidata 3.1, then it was exported in to Stata14.2 for analysis. Frequencies, proportions and descriptive statistics were used to explain the study population with the relevant variables. Binary logistic regression was used to analyze factors that affect the outcome variable. Variables with $p$ - value $<0.2$ with bivariable analysis were included to multivariable analysis. Explanatory variables which have $p$-value $<0.05$ in multivariable analysis were identified as a significant factor affecting the outcome variable (late stage) with $95 \%$ confidence level.

\section{Ethical clearance}

Ethical approval for this study was obtained from the Institutional Review Boards of school of nursing and midwifery, Addis Ababa University. The letter of permission was written from school of nursing and midwifery to the oncology center of TASH. Then, the oncology center chief administrator permitted to collect the data. The study was conducted without individual informed consent since data extraction were relied on chart review other than patients.

\section{Result}

\section{Sociodemographic characteristics of cervical cancer} patients

This study was conducted among 1057 cervical cancer patients presented within five consecutive years in oncology center of TASH. The mean age of study participants was 50 years with a minimum and maximum ages of 15 and 87 years respectively. More than half (58.1\%) of the patients came from urban area and about $26.5 \%$ of the patients came from Addis Ababa city. Nearly one sixth $(14.4 \%)$ were governmental workers, about two third $(62.9 \%)$ were married and $17.2 \%$ were substance users (Table 1).

\section{Clinical characteristics of cervical cancer patients}

Nearly one third (32.5\%) of patients had comorbidity at presentation and about $18.4 \%$ were HIV positive. Histologically, most (91\%) cervical cancer patients had squamous cell carcinoma (Table 2). Based on FIGO staging, about $3 \%$ of patients were with stage IA and nearly $30 \%$ patients were with stage IIIB (Fig. 1).

\section{Prevalence of late-stage presentation among cervical cancer patients}

The prevalence of Late-stage presentation among cervical cancer patients was 56.8\% [95\%CI (53.6-59.7)]. About $60.7 \%$ of patients with late stages were within $40-$ 49 age categories and about $68 \%$ came from rural area. Nearly three quarter $(73.3 \%)$ of late-stage patients came from Tigray region and about $42.5 \%$ were from Addis
Table 1 Socio demographic characteristics of cervical cancer patients in TASH oncology center, Ethiopia $(n=1057)$

\begin{tabular}{|c|c|c|c|c|c|}
\hline \multirow[t]{2}{*}{ Variables } & \multirow[t]{2}{*}{ Code } & \multicolumn{2}{|l|}{ Early stage } & \multicolumn{2}{|l|}{ Late stage } \\
\hline & & Frequency & $(\%)$ & Frequency & (\%) \\
\hline \multirow[t]{5}{*}{ Age } & $<30$ & 45 & 48.9 & 47 & 51.1 \\
\hline & $30-39$ & 100 & 45.7 & 119 & 54.3 \\
\hline & $40-49$ & 103 & 39.3 & 159 & 60.7 \\
\hline & $50-59$ & 111 & 45.3 & 134 & 54.7 \\
\hline & $\geq 60$ & 98 & 41.0 & 141 & 59.0 \\
\hline \multirow[t]{2}{*}{ Residency } & Urban & 315 & 51.3 & 299 & 48.7 \\
\hline & Rural & 142 & 32.1 & 301 & 68.0 \\
\hline \multirow[t]{6}{*}{ Region } & Amhara & 97 & 34.5 & 184 & 65.5 \\
\hline & Oromia & 149 & 43.7 & 192 & 56.3 \\
\hline & Tigray & 8 & 26.7 & 22 & 73.3 \\
\hline & SNNP & 31 & 32.6 & 64 & 67.4 \\
\hline & Addis Ababa & 161 & 57.5 & 119 & 42.5 \\
\hline & Others & 11 & 36.7 & 19 & 63.3 \\
\hline \multirow[t]{4}{*}{ Religion } & Orthodox & 267 & 42.4 & 363 & 57.8 \\
\hline & Muslim & 87 & 43.5 & 113 & 56.5 \\
\hline & protestant & 99 & 46.7 & 113 & 53.3 \\
\hline & Others & 6 & 40.0 & 9 & 60.0 \\
\hline \multirow[t]{2}{*}{ Occupation } & Employed & 73 & 48.0 & 79 & 52.0 \\
\hline & Unemployed & 384 & 42.4 & 521 & 57.6 \\
\hline \multirow[t]{2}{*}{ Marital status } & Married & 287 & 43.2 & 378 & 56.8 \\
\hline & unmarried & 170 & 43.4 & 222 & 56.6 \\
\hline \multirow[t]{5}{*}{ Children } & None & 20 & 50.0 & 20 & 50.0 \\
\hline & One & 23 & 33.3 & 46 & 66.7 \\
\hline & Two & 48 & 32.7 & 99 & 67.4 \\
\hline & Three & 177 & 49.0 & 184 & 51.0 \\
\hline & $>$ three & 189 & 43.0 & 251 & 57.0 \\
\hline \multirow[t]{2}{*}{ Substance } & User & 81 & 44.5 & 101 & 55.5 \\
\hline & None user & 376 & 43.0 & 499 & 57.0 \\
\hline
\end{tabular}

Table 2 Clinical characteristics of study participants in TASH oncology center, Ethiopia $(n=1057)$

\begin{tabular}{|c|c|c|c|c|c|}
\hline \multirow[t]{2}{*}{ Variables } & \multirow[t]{2}{*}{ Code } & \multicolumn{2}{|l|}{ Early stage } & \multicolumn{2}{|l|}{ Late stage } \\
\hline & & Frequency & $(\%)$ & Frequency & (\%) \\
\hline \multirow[t]{2}{*}{ Comorbidity } & Yes & 142 & 41.3 & 202 & 58.7 \\
\hline & No & 315 & 44.2 & 398 & 55.8 \\
\hline \multirow[t]{2}{*}{ Anemia } & Yes & 210 & 38.8 & 331 & 61.2 \\
\hline & No & 247 & 47.9 & 269 & 52.1 \\
\hline \multirow[t]{2}{*}{ Histology type } & Squamous cell & 414 & 43.2 & 545 & 56.8 \\
\hline & Adenocarcinoma & 43 & 43.9 & 55 & 56.1 \\
\hline \multirow[t]{2}{*}{ HIV status } & Negative & 383 & 44.4 & 480 & 55.6 \\
\hline & Positive & 74 & 38.1 & 120 & 61.9 \\
\hline
\end{tabular}




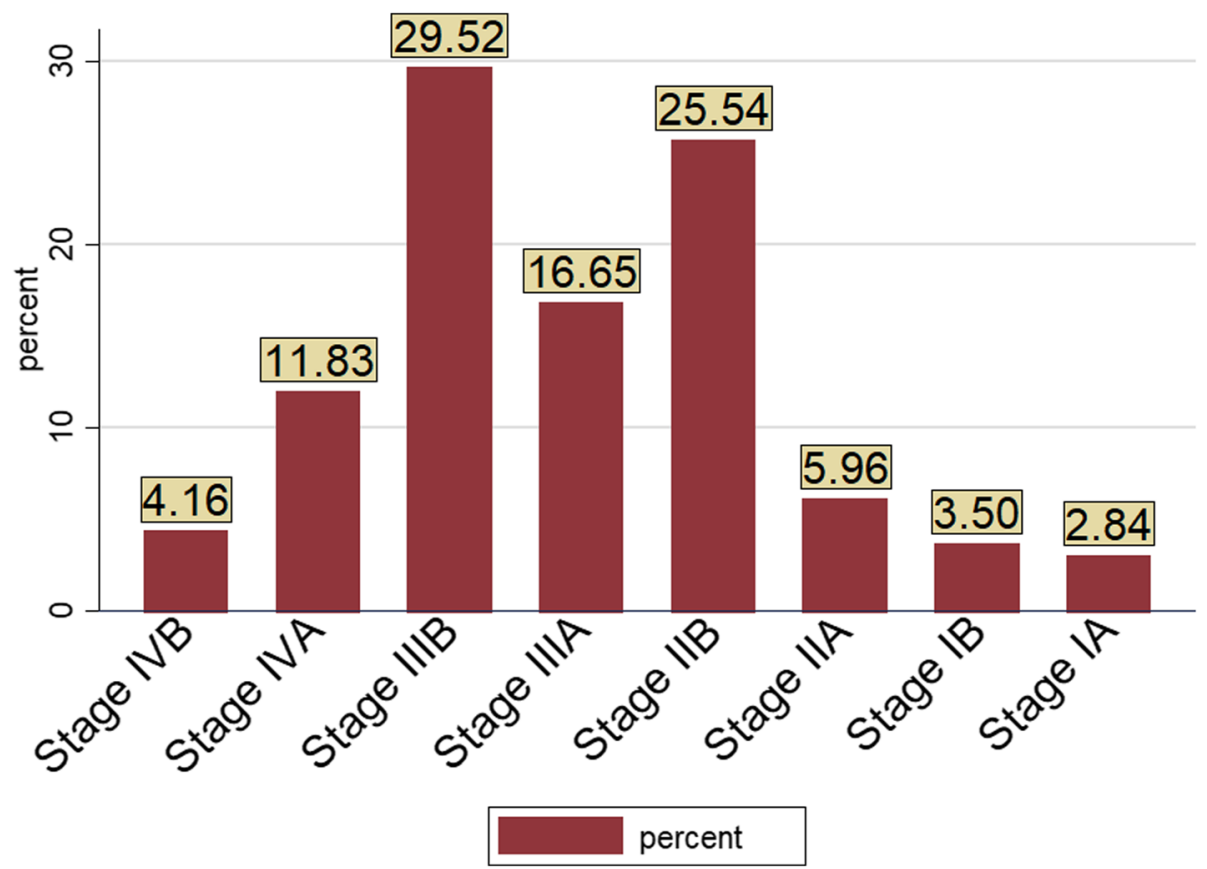

Fig. 1 FIGO Stages at presentation of cervical cancer patients in TASH oncology center, Ethiopia $(n=1057)$

Ababa city. Around 58\% of late-stage patients were none governmental employees and $56.8 \%$ were married. Roughly $56 \%$ of substance users presented with late stage, $59 \%$ of patients with comorbidity came at late stage and nearly $62 \%$ of HIV positive patients presented with late stage. Nearly $56.8 \%$ of patients with squamous cell carcinoma and $61 \%$ of anemic patients presented with late stage (Tables 1 and 2).

\section{Factors of late-stage presentation among cervical cancer patients}

Independent variables were analyzed individually with the outcome variable and the variables with the $p-<0.2$ were included in the multivariable binary logistic regression.

In multivariable binary logistic regression analysis, anemia, region, residency and age of the patients significantly affected the outcome variable (late-stage presentation) at $p$-value $<0.05$ with $95 \% \mathrm{CI}$.

The study revealed that cervical cancer patients with anemia presented with late stage 1.55 times [AOR = $1.55,95 \%$ CI (1.17-2.1)] more than who weren't anemic. Patients who came from Oromia region were at $35 \%$ [AOR $=0.65,95 \%$ CI $(0.46-0.913)]$ lower presented with late stage than patients who came from Amhara regional state. Similarly, patients who came from Addis Ababa city were at 50\% [AOR:0.5;95\%CI (0.337-0.729)] lower than those who came from Amhara regional state to present with late stage. Patients living in rural area presented with late stage 1.88 times [AOR:1.88;95\% (1.381-
2.56)] more than urban dwellers. Study Patients with age groups $\geq 60$ years presented with late stage 1.89 times [AOR:1.89;95\%CI (1.115-3.199] more than those with age group $<30$ years as a reference (Table 3 ).

\section{Discussion}

This study focused on the late-stage presentation and associated factors of cervical cancer patients in Ethiopia. In this study, about $57 \%$ cervical cancer patients presented with late stage. The current prevalence was lower than the studies conducted in Addis Ababa [4], Ghana [18], Tanzania [8], Nigeria [19] and Malaysia [20] with the prevalence's of $60.4,65.97,63.9,71.8$ and $60 \%$ respectively. But it is higher than the studies conducted in Morocco [21], India [9], England [22] and Mexico [23] with their prevalence's of 39.9, 45.4, 28 and 17.8\% respectively. The possible justification of the differences in prevalence could be due to sample size, study period and the accesses of cervical cancer information differences related to Addis Ababa and health care delivery policy, socioeconomic status variations of study participants, study period, sample size and study design differences in the case of other countries mentioned other than Addis Ababa.

Anemia, region, residency and age were the major contributing factors of late-stage presentation of cervical cancer patients in the current study. Cervical cancer patients who have anemia in this study presented with late stage than those who haven't anemia. This finding is supported by the study conducted in Tanzania [8]. This 
Table 3 Result of multivariable analysis of factors contributing to late-stage presentation of cervical cancer patients in TASH oncology center, Ethiopia $(n=1057)$

\begin{tabular}{|c|c|c|c|c|}
\hline Variables & Codes & AOR & $P$-value & $95 \% \mathrm{Cl}$ \\
\hline \multirow[t]{2}{*}{ Comorbidity } & No & & 1 & \\
\hline & Yes & 0.95 & 0.798 & $0.65-1.39$ \\
\hline \multirow[t]{2}{*}{ Anemic status } & No & & 1 & \\
\hline & Yes & 1.55 & 0.002 & $1.17-2.05$ \\
\hline \multirow[t]{2}{*}{ Marital status } & Unmarried & & 1 & \\
\hline & Married & 0.97 & 0.834 & $0.74-1.28$ \\
\hline \multirow[t]{5}{*}{ No. of children } & None & & 1 & \\
\hline & One & 1.63 & 0.251 & $0.71-3.74$ \\
\hline & Two & 1.65 & 0.187 & $0.78-3.48$ \\
\hline & Three & 0.76 & 0.432 & $0.38-1.52$ \\
\hline & more than 3 & 0.97 & 0.934 & $0.48-1.95$ \\
\hline \multirow[t]{2}{*}{ Substance } & None user & & 1 & \\
\hline & User & 0.92 & 0.673 & $0.64-1.33$ \\
\hline \multirow[t]{2}{*}{ Occupation } & None worker & & 1 & \\
\hline & Gov't worker & 0.91 & 0.626 & $0.62-1.33$ \\
\hline \multirow[t]{6}{*}{ Region } & Amhara & & 1 & \\
\hline & Oromia & 0.65 & 0.013 & $0.46-.91$ \\
\hline & Tigray & 1.25 & 0.620 & $0.52-3.02$ \\
\hline & SNNP & 1.02 & 0.940 & $0.61-1.71$ \\
\hline & Addis Ababa & 0.500 & $<0.001$ & $0.34-.73$ \\
\hline & Others & 0.93 & 0.865 & $0.41-2.13$ \\
\hline \multirow[t]{2}{*}{ Resident } & Urban & & 1 & \\
\hline & Rural & 1.88 & $<0.001$ & $1.38-2.56$ \\
\hline \multirow[t]{5}{*}{ Age } & $<30$ & & 1 & \\
\hline & $30-39$ & 1.35 & 0.261 & $0.79-2.29$ \\
\hline & $40-49$ & 1.50 & 0.124 & $0.89-2.51$ \\
\hline & $50-59$ & 1.35 & 0.258 & $0.80-2.26$ \\
\hline & $\geq 60$ & 1.89 & 0.018 & $1.12-3.19$ \\
\hline \multirow[t]{2}{*}{ HIV status } & Positive & & 1 & \\
\hline & Negative & 0.78 & 0.288 & $0.49-1.24$ \\
\hline
\end{tabular}

N.B:1 = reference category

will be as being anemic could mask the signs and symptoms of the patients and leads to delay of early diagnosis. Another justification might be diagnosis of anemia in the health facilities which aren't serving as the cancer center will delay appropriate referral as these facilities could try to treat anemia before referral. This delay of referral could associate to late-stage presentation of patients. But anemia by itself couldn't cause late-stage presentation despite it needs further investigation.

Patients who came from Oromia region and Addis Ababa city presented relatively with early stage than patients who came from Amhara region. This disparity will be as TASH is the only oncology center in Ethiopia and very far from Amhara region and relatively nearest to Addis Ababa and Oromia regions. As a result, patients in far area could get different problems to seek oncological treatment like transportation costs and treatment costs. This is supported by different literatures conducted in different countries [24, 25].

Residency was another contributing factor of late-stage presentation of cervical cancer patient. Patients who live in the rural area presented with more late stage than those who live in the urban area in this study. This result is in agreement with different studies [26, 27]. This might be due to patients who live from urban area can get different information about the symptoms and signs of cervical cancer as compared to rural dwellers.

Cervical cancer patients with advanced age ( $\geq 60$ years) presented with more late stage than those patients with age $<30$ years. This is supported by other researchers conducted in different settings $[28,29]$. This might be due to older women tend to believe that they are less vulnerable to cervical cancer and would not screen early. Another reason may be also due to older women are not seeking obstetrics and gynecology services in the postmenopausal years particularly women in rural areas where health care services are not readily accessible [30].

\section{Limitations}

Even though this study involved relatively large sample size, establishment of a causal relationship could not be possible since it is cross sectional study. In addition, the study was conducted in one setting which couldn't represent the whole areas of the country. Finally, the information was not recorded for the purpose of research that caused many chars with incomplete information.

\section{Conclusion}

The study revealed that the prevalence of late-stage cervical cancer presentation is high. late-stage presentation was significantly affected by anemic status of the patients, region where the patients came from, rural residency and advanced age. It is better to give special attention to patients with anemia, advanced age, rural dwellers and those who come from remote areas. Besides, cervical cancer education could be expanded to the rural dwellers, better to increase cancer treatment centers in all regions of the country.

\section{Abbreviations}

AOR: Adjusted Odds Ratio; FIGO: International Federation of Gynecology and Obstetrics; ASH: Tikur Anbesa Specialized Hospital; HIV: Human immune virus; HPV: Human papilloma virus

\section{Acknowledgments}

Our gratitude goes to School of Nursing and Midwifery, College of Health Sciences, Addis Ababa University for giving the chance to conduct this research. Authors duly acknowledge University of Gondar for giving the opportunity to attend the masters of clinical oncology nursing program in 
addition to a paid study leave. Authors thank also goes to Tikur Anbesa Specialized Hospital Managers and all cancer center staffs.

\section{Authors' contributions}

MW conceptualized the study and was involved in design, analysis, interpretation, report and manuscript writing. BF made substantial contribution to conception, analysis and interpretation of data, drafting the manuscript and critical revision for important intellectual content. All the authors read and approved the final manuscript.

\section{Funding}

Funding not applicable.

\section{Availability of data and materials}

Data will be available upon request from the corresponding author.

\section{Declarations}

Ethics approval and consent to participate

Ethical approval for this study was obtained from the Institutional Review Boards (IRB) of school of nursing and midwifery, Addis Ababa University. The letter of permission was written from school of nursing and midwifery to the oncology center of TASH. Then, the oncology center chief administrator allowed us to extract the data from the patients' chart. The study was conducted without individual informed consent since data extraction were totally relied on chart review.

\section{Consent for publication}

Not applicable.

\section{Competing interests}

The authors declare that they have no competing interests.

\section{Author details}

${ }^{1}$ School of Nursing, College of Medicine and Health Sciences, University of Gondar, Gondar, Ethiopia. ${ }^{2}$ Department of Pediatrics and Child Health Nursing, School of Nursing, College of Medicine and Health Sciences, University of Gondar, Gondar, Ethiopia.

Received: 25 February 2021 Accepted: 29 April 2021

Published online: 11 May 2021

\section{References}

1. Mboumba Bouassa RS, et al. Cervical cancer in sub-Saharan Africa: a preventable noncommunicable disease. Expert Rev Anti Infect Ther. 2017; 15(6):613-27.

2. Canfell K. Towards the global elimination of cervical cancer. Papillomavirus Res. 2019:8:100170.

3. Cohen PA, et al. Cervical cancer. Lancet. 2019;393(10167):169-82.

4. Dereje N, Gebremariam A. Factors associated with advanced stage at diagnosis of cervical cancer in Addis Ababa, Ethiopia: a population-based study. BMJ Open. 2020;10(10):e040645.

5. Dueñas-González A, Campbell S. Global strategies for the treatment of earlystage and advanced cervical cancer. Curr Opin Obstet Gynecol. 2016;28(1): $11-7$.

6. Dereje $\mathrm{N}$, et al. Extent and predictors of delays in diagnosis of cervical cancer in Addis Ababa, Ethiopia: a population-based prospective study. JCO Glob Oncol. 2020;6:277-84.

7. Birhanu Z, et al. Health seeking behavior for cervical cancer in Ethiopia: a qualitative study. Int J Equity Health. 2012;11:83.

8. Mlange $\mathrm{R}$, et al. Patient and disease characteristics associated with late tumour stage at presentation of cervical cancer in northwestern Tanzania. BMC Womens Health. 2015;16(1):1-6.

9. Chopra $\mathrm{S}$, et al. Locally advanced cervical cancer: a study of 5-year outcomes. Indian J Cancer. 2018;55(1):45.

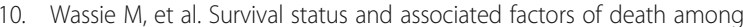
cervical cancer patients attending at Tikur Anbesa specialized Hospital, Addis Ababa, Ethiopia: a retrospective cohort study. BMC Cancer. 2019;19(1): 1221
11. Gizaw M, et al. Cervical cancer patients presentation and survival in the only oncology referral hospital, Ethiopia: a retrospective cohort study. Infect Agents Cancer. 2017;12(1):61.

12. Addissie TYAA. Survival and associated factors among cervical cancer patients in BlackLion Hospital, Addis Ababa, Ethiopia, 2008-2012, aretrospective longitudinal study. unpublished, 2014.

13. Yesuf DS, Lakew TJ, Yesuf KM. Survival analysis on the risk factors of women's with cervical cancer: a case study at Black Lion Hospital. Ethiopia: Addis Ababa; 2019.

14. Pecorelli S. Revised FIGO staging for carcinoma of the vulva, cervix, and endometrium. Int J Gynecol Obstet. 2009;105(2):103-4.

15. CSA, I. Ethiopia demographic and health survey, 2016 key indicators report Addis Ababa: CSA and ICF; 2016.

16. Charlson M, Foley W. Charlson Comorbidity Index: chart review version. 2018

17. Health OW. Promoting mental health: concepts, emerging evidence, practice: a report of the World Health Organization, Department of Mental Health and Substance Abuse in collaboration with the Victorian Health Promotion Foundation and the University of Melbourne. 2005.

18. Dunyo P, Effah K, Udofia EA. Factors associated with late presentation of cervical cancer cases at a district hospital: a retrospective study. BMC Public Health. 2018:18(1):1156.

19. Anorlu R, et al. Late presentation of patients with cervical cancer to a tertiary hospital in Lagos: what is responsible? Eur J Gynaecol Oncol. 2004 25(6):729-32.

20. Devi B, Tang T, Corbex M. Reducing by half the percentage of late-stage presentation for breast and cervix cancer over 4 years: a pilot study of clinical downstaging in Sarawak Malaysia. Ann Oncol. 2007;18(7):1172-6.

21. Ouasmani F, et al. Determinants of patient delay in seeking diagnosis and treatment among Moroccan women with cervical cancer. Obstet Gynecol Int. 2016:2016:1.

22. Lim AW, et al. Delays in diagnosis of young females with symptomatic cervical cancer in England: an interview-based study. Br J Gen Pract. 2014; 64(627):e602-10.

23. Unger-Saldaña K, Alvarez-Meneses A, Isla-Ortiz D. Symptomatic presentation, diagnostic delays and advanced stage among cervical cancer patients in Mexico. J Glob Oncol. 2018;4:221s (American Society of Clinical Oncology).

24. Ambroggi $M$, et al. Distance as a barrier to cancer diagnosis and treatment: review of the literature. Oncologist. 2015:20(12):1378.

25. Massarweh NN, et al. Association between travel distance and metastatic disease at diagnosis among patients with colon cancer. J Clin Oncol. 2014 32(9):942.

26. Sathwara JA, et al. Sociodemographic factors and late-stage diagnosis of breast cancer in India: a hospital-based study. Indian J Med Paediatr Oncol. 2017;38(3):277.

27. Tesfaw A, et al. Patient delay and contributing factors among breast cancer patients at two cancer referral centres in Ethiopia: a cross-sectional study. J Multidiscip Healthc. 2020;13:1391.

28. Partridge $\mathrm{AH}$, et al. The effect of age on delay in diagnosis and stage of breast cancer. Oncologist. 2012;17(6):775.

29. McGuire A, et al. Effects of age on the detection and management of breast cancer. Cancers. 2015;7(2):908-29.

30. Ibrahim A, et al. Predictors of cervical cancer being at an advanced stage at diagnosis in Sudan. Int J Womens Health. 2011;3:385-9.

\section{Publisher's Note}

Springer Nature remains neutral with regard to jurisdictional claims in published maps and institutional affiliations. 